\title{
Commentary: Surgical repair of thoracoabdominal aortic aneurysm-Still room for improvement
}

\author{
Hans-Joachim Schäfers, MD
}

\footnotetext{
From the Department of Thoracic and Cardiovascular Surgery, Saarland University Medical Center, Homburg/ Saar, Germany.

Disclosures: Author has nothing to disclose with regard to commercial support.

Received for publication Feb 8, 2019; accepted for publication Feb 11, 2019; available ahead of print April 5, 2019.

Address for reprints: Hans-Joachim Schäfers, MD, Department of Thoracic and Cardiovascular Surgery, Saarland University Medical Center, Kirrberger Straße 100, D-66421 Homburg/Saar, Germany (E-mail: h-j.schaefers@ uks.eu).

J Thorac Cardiovasc Surg 2020;159:14-5

$0022-5223 / \$ 36.00$

Copyright (C) 2019 by The American Association for Thoracic Surgery

https://doi.org/10.1016/j.jtcvs.2019.02.053
}

Four decades ago, surgical repair of thoracoabdominal aortic aneurysm (TAA) was one of the biggest challenges in cardiovascular surgery. ${ }^{1}$ Apart from in-hospital mortality, spinal cord damage (SCD) was the most dreaded complication. ${ }^{1}$ In the meantime, much progress has been made, and the pathophysiology of SCD is now much better understood. Different approaches have been developed to protect against SCD, such as distal perfusion, staged clamping, hypothermia, and cerebrospinal fluid drainage. ${ }^{2,3}$ Reattachment of intercostal arteries is believed by some to be the most critical intervention, ${ }^{2,3}$ even though this has been discussed controversially. ${ }^{4,5}$ The impression has been created that-at least in very experienced hands-TAA repair has become a relatively safe procedure.

In view of this optimism, the series of Coselli and coauthors ${ }^{6}$ presented in this issue of the Journal, the largest on TAA type II repair published to date, presents a seemingly sobering view. With an operative mortality of $10 \%$ and an incidence of SCD that is close to $14 \%$, the risk of serious or devastating complications is still substantial. Thus, conventional, open surgery can be seen in a very critical light. The cumulative incidence of complications can be interpreted as a strong message that we should emphasize and primarily use interventional treatment in treating this challenging patient cohort.

On the other hand, the conclusion is not that simple. Interestingly, $40 \%$ of the reported SCDs occurred as delayed events, and in many instances these events were related to hypotension or low cardiac output, ${ }^{6}$ which theoretically should be avoidable. Reimplantation of the intercostal arteries proved protective against $\mathrm{SCD}^{6}$; thus, better preoperative definition of the critical intercostal pair or pairs could possibly enhance this protective effect even further. Finally, the probability of SCD was increased in the presence of atherosclerosis and diabetes mellitus, ${ }^{6}$ that is, diseases that involve endothelial dysfunction. SCD occurred less frequently in younger patients with less atherosclerosis, consistent with previous observations of profile. ${ }^{6}$

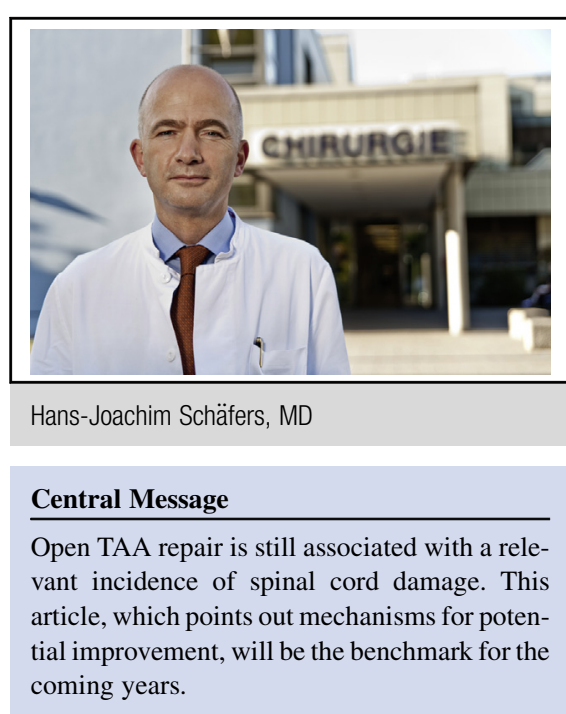

See Article page 1.

the same group. ${ }^{7}$ It is thus conceivable that the risk of SCD after surgical TAA repair can be decreased further by specific measures, including patient selection.

By comparison, the current experience with endovascular treatment of TAA is very limited. ${ }^{8,9}$ Lower mortalities and lower SCD rates than with surgical repair have been published, albeit in very heterogenous patient populations with few type II TAAs. ${ }^{8,9}$ The results of endovascular therapy will have to be compared against the current data presented here by Coselli and coauthors ${ }^{6}$ as the benchmark. More importantly, late results will have to be taken into consideration. Thoracic endovascular aortic repair has been associated with significantly increased late mortality, ${ }^{10}$ and the role of endoleaks in contributing to this association is as yet unclear. Interventional treatment of abdominal aneurysm has been associated with a variable but relevant incidence of late rupture or the need for aortic reintervention. ${ }^{10}$ On an anecdotal basis, treatment failure has also been observed more than casually after intervention of TAA. ${ }^{7}$ For endovascular treatments for TAA to show equivalent early results, they will have to prove successful in a cohort with similar patient

Thus, surgical repair of type II TAA currently remains the criterion standard against which new approaches have to be 
compared. The current analysis of Coselli and colleagues ${ }^{6}$ points out that despite 4 decades of improvement in TAA surgery, there is still room for potential improvement in its results.

\section{References}

1. Crawford ES. Thoraco-abdominal and abdominal aneurysms involving renal, superior mesenteric, and celiac arteries. Ann Surg. 1974;179:763-72.

2. Safi HJ, Miller CC III, Huynh TT, Estrera AL, Porat EE, Winnerkvist AN, et al. Distal aortic perfusion and cerebrospinal fluid drainage for thoracoabdominal and descending thoracic aortic repair: ten years of organ protection. Ann Surg. 2003;238:372-80; discussion 380-1.

3. Coselli JS, LeMaire SA, Preventza O, de la Cruz KI, Cooley DA, Price MD, et al. Outcomes of 3309 thoracoabdominal aortic aneurysm repairs. J Thorac Cardiovasc Surg. 2016;151:1323-37.

4. Griepp RB, Griepp EB. Spinal cord perfusion and protection during descending thoracic and thoracoabdominal aortic surgery: the collateral network concept. Ann Thorac Surg. 2007;83:S865-9; discussion S890-2.
5. Etz CD, Weigang E, Hartert M, Lonn L, Mestres CA, Di Bartolomeo R, et al. Contemporary spinal cord protection during thoracic and thoracoabdomina aortic surgery and endovascular aortic repair: a position paper of the vascular domain of the European Association for Cardio-Thoracic Surgery†. Eur J Cardiothorac Surg. 2015;47:943-57.

6. Coselli JS, Green SY, Price MD, Zhang Q, Preventza O, de la Cruz K, et al Spinal cord deficit after 1114 extent type II open thoracoabdominal aortic aneurysm repairs. J Thorac Cardiovasc Surg. 2020;159:1-13.

7. Coselli JS, Amarasekara HS, Green SY, Price MD, Preventza O, de la Cruz KI, et al. Open repair of thoracoabdominal aortic aneurysm in patients 50 years old and younger. Ann Thorac Surg. 2017;103:1849-57.

8. Motta F, Crowner JR, Kalbaugh CA, Marston WA, Pascarella L, McGinigle KL, et al. Outcomes and complications after fenestrated-branched endovascular aortic repair. J Vasc Surg. 2019;70:15-22.

9. Goodney PP, Travis L, Lucas FL, Fillinger MF, Goodman DC, Cronenwett JL, et al. Survival after open versus endovascular thoracic aortic aneurysm repair in an observational study of the Medicare population. Circulation. 2011;124: 2661-9.

10. Deery SE, Schermerhorn ML. Open versus endovascular abdominal aortic aneurysm repair in Medicare beneficiaries. Surgery. 2017;162:721-31. 